\title{
Role of proton MR spectroscopy in spinal cord lesions: A guarded espousal
}

Sir,

I read with great interest the article titled "3T proton MR spectroscopy evaluation of spinal cord lesions" by Sathyanathan et al. published in the July-September, 2018 issue of the Indian Journal of Radiology and Imaging. ${ }^{[1]}$ The manuscript is well written and informative. The authors have narrated the MR spectroscopy (MRS) protocol and patterns in various intramedullary spinal lesions in a very efficient manner. However, I would like to make the following contributions and observations pertinent to the study.

In their study cohort of 50 patients, the authors have investigated spectral pattern on intramedullary spinal cord lesions. They designated four of them as schwannoma, which is an extramedullary lesion. Literature shows very few case reports of intramedullary schwannoma, which may be found in neurofibromatosis. ${ }^{[2,3]}$ Even in the subsequent discussion, the MRS pattern of these lesions is not elaborated. So, it will be of great help if authors could clarify my doubts in this regard.

The present study ${ }^{[1]}$ defines the changes in the metabolites in different spinal lesions based on the deviation in their peak values from the normal spectra. In the previous few studies, ${ }^{[4,5]}$ the results have been expressed in terms of metabolite ratios, which is an absolute quantification method. Therefore, I would like to know about the authors' experience in evaluating the metabolite ratios and their feasibility pertaining to the study.

High signal-to-noise ratio is addressed in the present study ${ }^{[1]}$ by the use of high magnetic field strength $(3 \mathrm{~T})$. However, there are spectral reliability indices such as Cramér-Rao lower bounds of each metabolite, mean, and standard deviation of the spectral line width, the coefficient of variations of the measurements, and the group average of the spectra. ${ }^{[5]}$ These quality indicators can be used in future studies for enhancing the spectral quality and dependability.

\section{Financial support and sponsorship}

Nil.
Conflicts of interest

There are no conflicts of interest.

Arjit Agarwal
Department of Radiodiagnosis, Teerthanker Mahaveer
Medical College \& Research Center, Teerthanker Mahaveer
University, Moradabad, UP, India.
E-mail: drarjit26@gmail.com

\section{References}

1. Sathyanathan BP, Raju BP, Natarajan K, Ranganathan R. 3T proton MR spectroscopy evaluation of spinal cord lesions. Indian J Radiol Imaging 2018;28:285-95.

2. Koeller KK, Rosenblum RS, Morrison AL. Neoplasms of the spinal cord and filum terminale: Radiologic-pathologic correlation. Radiographics 2000;20:1721-49.

3. Nayak R, Chaudhuri A, Chattopadhyay A, Ghosh SN. Thoracic intramedullary schwannoma: A case report and review of literature. Asian J Neurosurg 2015;10:126-8.

4. Marliani AF, Clementi V, Albini-Riccioli L, Agati R, Carpenzano M, Salvi F, et al. Quantitative cervical spinal cord 3T proton MR spectroscopy in multiple sclerosis. AJNR Am J Neuroradiol 2010;31:180-8.

5. Hock A, Henning A, Boesiger P, Kollias SS. 1H-MR spectroscopy in the human spinal cord. Am J Neuroradiol 2013;34:1682-9.

This is an open access journal, and articles are distributed under the terms of the Creative Commons Attribution-NonCommercial-ShareAlike 4.0 License, which allows others to remix, tweak, and build upon the work non-commercially, as long as appropriate credit is given and the new creations are licensed under the identical terms.

\begin{tabular}{|l|l|}
\hline \multicolumn{2}{|c|}{ Access this article online } \\
\hline Quick Response Code: & \\
\hline & Website: \\
\hline & www.jri.org \\
& \\
\hline
\end{tabular}

Cite this article as: Agarwal A. Role of proton MR spectroscopy in spinal cord lesions: A guarded espousal. Indian J Radiol Imaging 2018;28:481. ๑) 2018 Indian Journal of Radiology and Imaging | Published by Wolters Kluwer - Medknow 